\title{
Numerical Simulation 3D of Local Scour around Subsea Caisson Structures in Steady Currents and Waves
}

\author{
Xuyen Hoang* \\ College of Harbor, Coastal and Offshore Engineering \\ Hohai University, No.1 Xikang Road \\ Nanjing 210098, China \\ *Corresponding author
}

\begin{abstract}
This paper studied the local scour processes at subsea structures using using the computational fluid dynamics codes (OPENSOURCE CODE). The model solved the fully threedimensional, Reynolds-averaged Navier-Stokes equation closed with the LES model. Stokes and Cnoidal Waves were generated using Fenton's Fourier series method. Two empirical models must be used to compute the boundary layer at the interface and bed-load transport. We used the types of structured Cartesian grids. The velocity amplification at the corners is the dominant flow mechanism that controls the maximum scour depth. The results were agreement with the experimental study.
\end{abstract}

Keywords-local scour; horseshoe vortex; velocity amplification

\section{INTRODUCTION}

When a structure is placed in the flow pattern resulting in one or more of the phenomena: the flow accelerations at the corners, the horseshoe vortex at the upstream boundary and the vortex shedding behind the caisson. The investigations of obstruction have been presented by [1]; [2]. Several formulas for estimating local scour depth have been proposed by dimensional analyses by [2] or the analytical approaches [3]. More extensive studies which occur around a bridge pier have been classified: (1) scouring parameters concerning flow or sediment characteristics [4]; (2) effect of pier characteristics on scour depth [5]; (3) estimation of maximum scour depth [4] and most of the studies and (4) temporal variation of scour depth or geometry [6]. Two-dimensional numerical analyses by [7] or three-dimensional models with the hydrostatic assumption by [8] cannot reliably compute flow fields near the structure. Stokes and Cnoidal Waves were generated using Fenton's Fourier series method. Because it is not possible to compute the flow dynamics about each individual grain of sediment and it is oftentimes difficult to compute the boundary layer at the interface, an empirical model must be used. This study is to answer the following questions: (1) What is the dominant flow mechanism that controls the maximum scour depth? Does the horseshoe vortex play a dominant role in the scour process?(2) How does the process of local scour occur around Caissons?

\section{NUMERICAL MODEL}

\section{A. Flow Model}

The governing equations for flow calculation are the Reynolds - Averaged Navier-Stokes equations

\section{1) Momentum equations}

The equations of motion for the fluid velocity components $(\mathrm{u}, \mathrm{v}, \mathrm{w})$ in the three coordinate directions are the NavierStokes equations with some additional terms:

$\frac{\partial u}{\partial t}+\frac{1}{V_{f}}\left\{u A_{x} \frac{\partial u}{\partial x}+v A_{y} \frac{\partial u}{\partial y}+w A_{z} \frac{\partial u}{\partial z}\right\}=-\frac{1}{\rho} \frac{\partial p}{\partial x}+G_{x}+f_{x}-b_{x}-\frac{R_{S O R}}{\rho V_{f}}\left(u-u_{w}-\delta u_{s}\right)$

$\frac{\partial v}{\partial t}+\frac{1}{V_{f}}\left\{u A_{x} \frac{\partial v}{\partial x}+v A_{y} \frac{\partial v}{\partial y}+w A_{z} \frac{\partial v}{\partial z}\right\}=-\frac{1}{\rho} \frac{\partial p}{\partial y}+G_{y}+f_{y}-b_{y}-\frac{R_{S O R}}{\rho V_{f}}\left(v-v_{w}-\delta v_{s}\right)$

$\frac{\partial w}{\partial t}+\frac{1}{V_{f}}\left\{u A_{x} \frac{\partial w}{\partial x}+v A_{y} \frac{\partial w}{\partial y}+w A_{z} \frac{\partial w}{\partial z}\right\}=-\frac{1}{\rho} \frac{\partial p}{\partial z}+G_{z}+f_{z}-b_{z}-\frac{R_{S O R}}{\rho V_{f}}\left(w-w_{w}-\delta w_{s}\right)(3)$

In these equations: $\left(G_{x}, G_{y}, G_{z}\right)$ are body accelerations; $\left(f_{x}\right.$, $f_{y}, f_{z}$ ) are viscous accelerations; (bx, by, bz) are flow losses in porous media, and the final terms account for the injection of mass at a source represented by a geometry component.

2) Mass Continuity Equation

$$
\frac{\partial}{\partial x}\left(u A_{x}\right)+\frac{\partial}{\partial y}\left(v A_{y}\right)+\frac{\partial}{\partial z}\left(w A_{z}\right)=\frac{R_{S O R}}{\rho}
$$

Where: $\rho$ is the fluid density, $R_{S O R}$ is a mass source. The velocity components $(\mathrm{u}, \mathrm{v}, \mathrm{w})$ are in the coordinate directions $(\mathrm{x}, \mathrm{y}, \mathrm{z}) . \mathrm{A}_{\mathrm{x}} ; \mathrm{A}_{\mathrm{y}}$ and $\mathrm{A}_{\mathrm{z}}$ are area fractions for flow in the $\mathrm{x}, \mathrm{y}$ and $\mathrm{z}$ directions.

\section{B. Sediment Scour Model}

The sediment scour model estimates the motion of sediment flow by predicting the erosion, advection and deposition of sediment.

$$
\frac{\partial c_{s, i}}{\partial t}+\nabla \cdot\left(-\bar{u} c_{s, i}\right)=0
$$

Where $c_{s, i}$ is the concentration of the suspended sediment, in units of mass per unit volume and $u$ is the mean velocity of the fluid/sediment mixture. Therefore, one can write momentum balances for each sediment species and the fluidsediment mixture: 


$$
\begin{gathered}
\frac{\partial u_{s, i}}{\partial t}+\bar{u} \cdot \nabla u_{s, i}=-\frac{1}{\rho_{s, i}} \nabla P+F-\frac{K_{i}}{f_{s, i} \rho_{s, i}} u_{r, i} \\
\frac{\partial \bar{u}}{\partial t}+\bar{u} \cdot \nabla \bar{u}=-\frac{1}{\rho} \nabla P+F
\end{gathered}
$$

Here: $u_{s, i}$ is the velocity of sediment species $i ; \rho_{s, i}$ is the density of the sediment material; $f_{s, i}$ is the volume fraction of sediment species $\mathrm{i}$; $\mathrm{P}$ is the pressure; $\mathrm{K}$ is the drag function.

The drift velocity is computed from the relative velocity using the definition of the drift and relative velocities:

$$
u_{d r i f t, i}=\left(1-f_{s, i}\right) u_{r, i}^{e f f}-\sum_{j=1}^{N(-i)} f_{s, j} u_{r, j}
$$

\section{Turbulence Transport Models}

Large Eddy Simulation Model. The filter provides a formal definition of the averaging process and separates the resolvable scales from the sub grid scales. We use filtering to derive the resolvable-scale equation (Wilcox, D.C - 2006). For incompressible flow, the continuity and Navier-Stokes equations assume the following form.

$$
\left.\begin{array}{c}
\frac{\partial \bar{u}_{i}}{\partial t}+\frac{\partial}{\partial x_{j}}\left(\bar{u}_{i} \cdot \bar{u}_{j}\right)=-\frac{1}{\rho} \frac{\partial P}{\partial x_{i}}+\frac{\partial}{\partial x_{j}}\left[v \frac{\partial \bar{u}_{i}}{\partial x_{j}}+\tau_{i j}\right] \\
\tau_{i j}=-\left(Q_{i j}-\frac{1}{3} Q_{k k} \delta_{i j}\right) \\
P=\bar{p}+\frac{1}{3} \rho Q_{k k} \delta_{i j} \\
Q i j=R_{i j}+C_{i j}
\end{array}\right\}
$$

$\mathrm{C}_{\mathrm{ij}}, \mathrm{R}_{\mathrm{ij}}$ : The tensors are known as the Cross-term stress and the Sub grid-Scale Reynolds stress.

\section{$\mathrm{Q}_{\mathrm{ij}}$ : LES stress tensor.}

P: Mean static pressure.

$\tau_{\mathrm{ij}}$ : Specific Reynolds stress tensor.

The Large Eddy Simulation (LES) model of turbulence a rose from atmospheric modeling efforts. The basic idea is that one should directly compute all turbulent flow structures that can be resolved by the computational grid and only approximate those features that are too small to be resolved (Smagorinsky-1963). When using the LES model, it is important to remember that the model is inherently three dimensional and time-dependent. Furthermore, fluctuations must be initialized and/or input at inflow boundaries.

The filter provides a formal definition of the averaging process and separates the resolvable scales from the sub grid scales.

$$
L=\left(\delta_{x} \delta_{y} \delta_{z}\right)^{\frac{1}{3}}
$$

And scales velocity fluctuations by the magnitude of $\mathrm{L}$ times the mean shear stress. These quantities are combined into the LES kinematic eddy viscosity

$$
v_{T}=(c L)^{2} \cdot \sqrt{2 e_{i j} 2 e_{i j}}
$$

where $\mathrm{c}$ is the range of 0.1 to 0.2 and eij denotes the strain rate tensor. This kinematic eddy viscosity is incorporated into the dynamic viscosity.

$$
\mu=\rho\left(v+v_{T}\right)
$$

\section{Stokes and Cnoidal Waves Generator}

Cnoidal Waves is a nonlinear oscillatory Wave in shallow water, which has sharper crests and flatter troughs than a Stokes Waves. It is generated using Fenton's Fourier series method (Fenton-1999). Let $\mathrm{d}$ and $\mathrm{H}$ represent the undisturbed water depth and the Waves height (measured vertically from Waves trough to Waves crest), respectively. A stationary reference system $(\mathrm{x}, \mathrm{z})$ is established in such a way that its origin is fixed at the bottom, $+x$ goes horizontally in the Waves propagation direction, and $+z$ directs vertically upward (when using the code, we can place the coordinate origin at any location but $+\mathrm{z}$ must be in the upward direction). A current is assumed to exist and its $\mathrm{x}$-component $\mathrm{u}$ is a constant. The Waves speed $\mathrm{c}$ and the angular Waves frequency $\omega$ are related to other parameters as

$$
\begin{gathered}
\omega=\frac{2 \pi}{T}=c k \\
c=\frac{\lambda}{T}
\end{gathered}
$$

where: $\lambda$ is the waves length; $k$ is the waves number and $T$ is the waves period.

The nonlinear equation system is iteratively solved using Newton's method. Once the unknown variables are obtained, the transient water velocity in the stationary $\operatorname{system}(\mathrm{x}, \mathrm{z})$ is calculated using the following equations:

$$
\begin{gathered}
u(x, z, t)=\bar{u}+\sqrt{\frac{g}{k}} \sum_{j=1}^{N} j B_{j} \frac{\cosh j k z}{\cosh j k d} \cos j k(x-c t) \\
\omega(x, z, t)=\sqrt{\frac{g}{k}} \sum_{j=1}^{N} j B_{j} \frac{\sinh j k z}{\cosh j k d} \sin j k(x-c t)
\end{gathered}
$$

Water elevation $\eta(\mathrm{x} ; \mathrm{t})$ is calculated using the Fourier transformation

$$
\eta(x, t)=\frac{E_{1}}{2}+\sum_{j=2}^{N+1} E_{j} \cos [(j-1) k(x-c t)]
$$

where $\mathrm{Ej}$ is calculated by numerical integration

$$
E_{j}=\frac{2}{N} \sum_{n=1}^{N+1} " \eta_{n} \cos \frac{(j-1)(n-1) \pi}{N}(\text { for } j=1,2 \ldots, N+1)
$$




\section{NUMERICAL SIMULATION AND VALIDATION}

FIGURE. 1 shows a computational domain for calculating scour around a subsea caisson. At the inlet boundary, the transverse and the vertical velocity components are set to zero. The computational domain $(340 \times 200 \times 50) \mathrm{cm}$ was divided into hexahedron 8-node tri-linear elements. The shapes of the caisson $(X, Y)$ : $40 \mathrm{~cm} \times 20 \mathrm{~cm} ; Z=20 \mathrm{~cm}$; Steady currents $\mathrm{V}=$ $35 \mathrm{~cm} / \mathrm{s}$; Waves heights $=8 \mathrm{~cm}$. Water depth $\mathrm{Hn}=50 \mathrm{~cm}$; Waves period $=2.5 \mathrm{~s}$; Mean fluid depth $=65 \mathrm{~cm}$;

TABLE I. THE SCOUR RESULTS ARE SUMMARIZED

\begin{tabular}{|ll|l|l|l|l|l|l|}
\hline \multicolumn{2}{|c|}{ Cases } & \multicolumn{3}{c|}{ Simulation Results } & \multicolumn{3}{c|}{ Experimental Results } \\
\hline \multicolumn{2}{|c|}{ Time } & $2 \mathrm{~s}$ & $5 \mathrm{~s}$ & $23.76 \mathrm{~s}$ & $10 \mathrm{~min}$ & $1 \mathrm{~h}$ & $5 \mathrm{~h}$ \\
\hline $\begin{array}{l}\text { Scour depth cm } \\
(\mathrm{cm})\end{array}$ & 3 & 6 & 12 & 4 & 8 & 15 \\
\hline
\end{tabular}

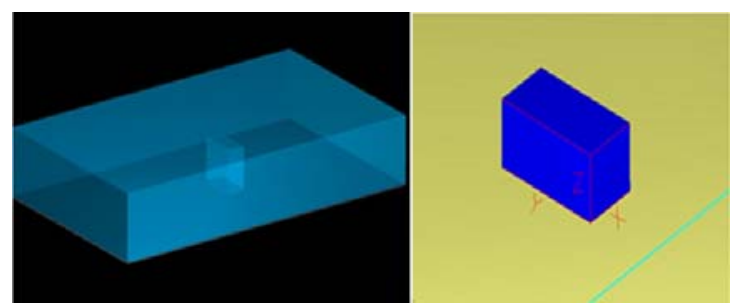

FIGURE I. ILLUSTRATES OF MODELS

Sand layer Hsand $=20 \mathrm{~cm}$; Specific gravity $(\mathrm{s})=2.69$; Drag coefficient $=0.5$; Entrainment coefficient $=5$; Bed load coefficient $=10$; Angle of repose $($ Degrees $)=35$; Diameter D50 $\mathrm{mm}=0.4$; Critical shields parameter $=0.066$.

- Group 1: P11 Velocity (without Waves).

- Group 2: P22 Waves (without velocity).

Some parameters of experimental tests (B4) [9] are as follows: Water depth $\mathrm{Hn}=50 \mathrm{~cm}$; Velocity in $\mathrm{X}$ axis $\mathrm{Vx}=32.5 \mathrm{~cm} / \mathrm{s} ;$ Specific gravity $(\mathrm{s})=2.67$; Diameter $\mathrm{D} 50$ $\mathrm{mm}=0.135$; Critical shields parameter $=0.0625$.

\section{3D Numerical Simulation RESUlts}

The determination of stable scour depth: Stable scour depth is identified when mean kinetic energy is constant (See FIGURE. 2h).

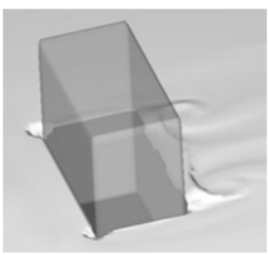

(a)

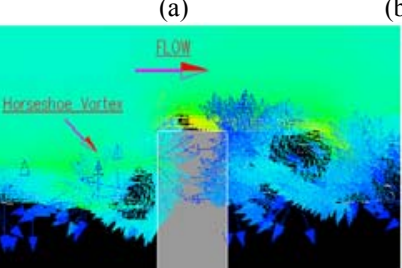

(d)

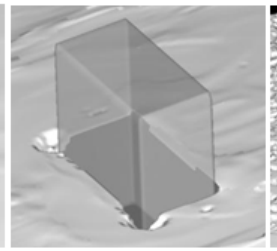

(b)

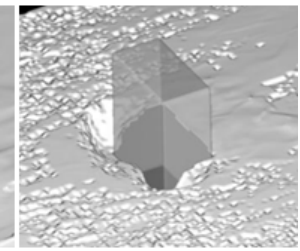

(c)

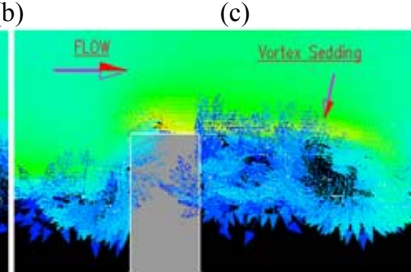

(e)

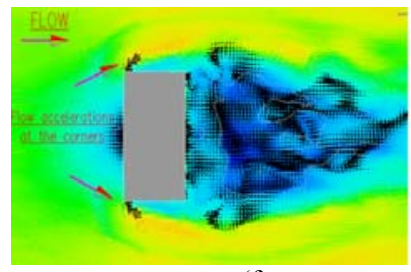

(f)

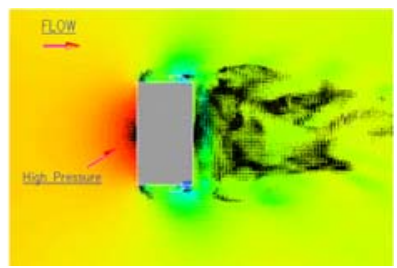

$(\mathrm{g})$

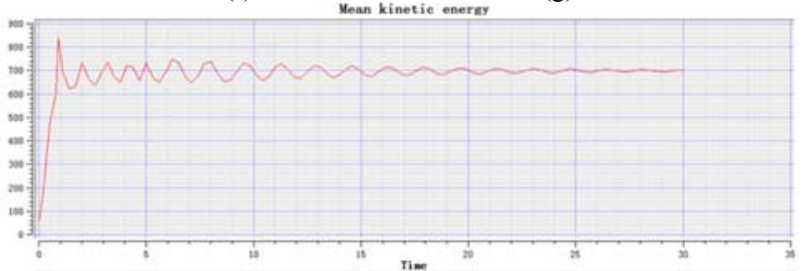

(h)

(a) Scour process at $\mathrm{t}=2 \mathrm{~s}$; (b) Scour process at $\mathrm{t}=5 \mathrm{~s}$; (c) Scour process at $\mathrm{t}$ $=23.76 \mathrm{~s}$; (d) Horseshoe vortex at the upstream; (e) Vortex shedding at the downstream; (f) Plan view of Depth-Averaged Velocity Magnitude; (g) Plan

view of Pressure Magnitude; (h) Mean kinetic energy - Time Graph

FIGURE II. PHOTOGRAPHS OF P11 SIMULATION DURING SCOUR

\section{Group 1 P11:}

Scour process started at two upstream corners of the caisson. After $2 \mathrm{~s}$ two distinct scour pits around the two upstream corners were observed clearly and their depths were about $3 \mathrm{~cm}$ (FIGURE. 2a; 3a; 3d). The central part of the upstream boundary was still flat until $5 \mathrm{~s}$ (FIGURE. 2b). Three flow mechanisms contribute to scour around a caisson

- The flow accelerations at the corners. They appeared at $1 / 3$ the horizontal length from the upstream corners (FIGURE. 2f). Fully non-hydrostatic pressure distributions closed and introduced the effect at sediment transport processes. (FIGURE. 2g)

- The horseshoe vortex at the upstream boundary (FIGURE. 2d) and vortex shedding behind (FIGURE. 2e). The horseshoe vortex plays a non-dominant role in the scour process. After 5 s of scour (See more FIGURE. 3b, 3e), the two scour holes at the upstream cornerswere deepened with the central part of the upstream and toward the two downstream corners. After 23.76 $\mathrm{s}$ of scour, the equilibrium scour depths at the two upstream corners were about $12 \mathrm{~cm}$ (FIGURE. 2c; 3c; 3f). The scour depth at the centre of the upstream boundary was $8 \mathrm{~cm}$.

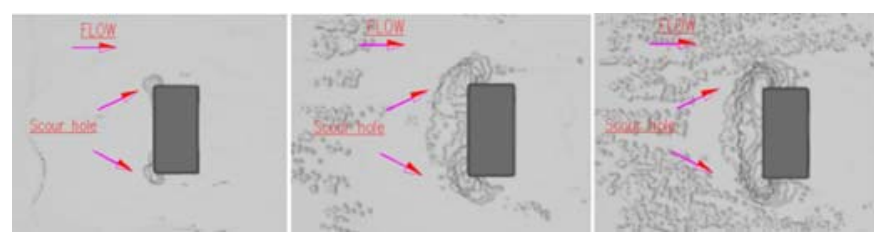

(a)

(b)

(c) 


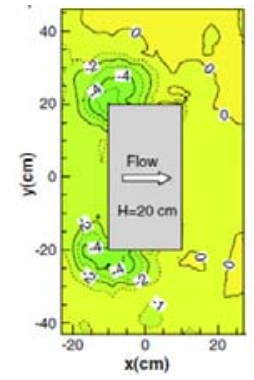

(d)

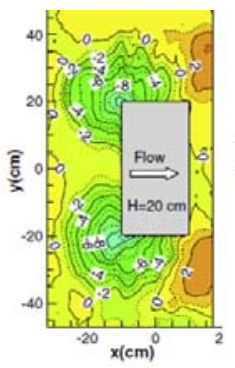

(e)

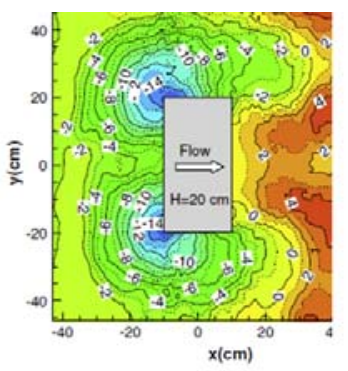

(f) (a) Plan view (PV) of Scour depth at $\mathrm{t}=2 \mathrm{~s}$; (b) PV of Scour depth at $\mathrm{t}=11 \mathrm{~s}$; (c) PV of Scour depth at $t=23.76 \mathrm{~s}$; (d) Scour process at $t=10 \mathrm{~min}$; (e) Scour process at $\mathrm{t}=1 \mathrm{~h}$; (f) Scour process at $\mathrm{t}=5 \mathrm{~h}$

FIGURE III. PLAN VIEW OF P11 (A, B, C); CONTOURS OF BED LEVEL TEST B4 [9] (D, E, F)

\section{Group 1 P21:}

Scour process started at four upstream and downstream corners. After $3 \mathrm{~s}$, two distinct scour pits around the two upstream corners were observed clearly and their depths were $3 \mathrm{~cm}$ (FIGURE. 5a). The flow mechanism contribute to scour around a caisson is the flow accelerations at the corners (Upstream and Downstream). Fig $4 \mathrm{c}$, d. The horseshoe vortex at the upstream boundary (FIGURE. 4 a) and vortex shedding behind the caisson (FIGURE. 4 b). They are very weak and do not participate in the process causing scour. After $28 \mathrm{~s}$ of scour, the equilibrium scour depths at the two upstream corners were $7 \mathrm{~cm}$ (FIGURE. 5b). After $60 \mathrm{~s}$, the scour depths at the two upstream corners were still about $7.1 \mathrm{~cm}$ (FIGURE. 5c).

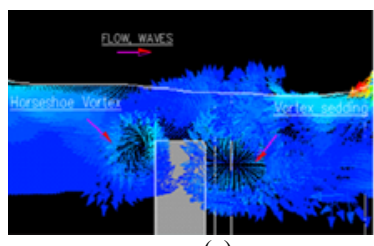

(a)

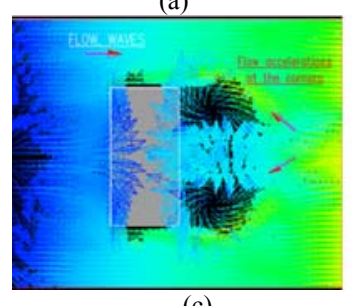

(c)

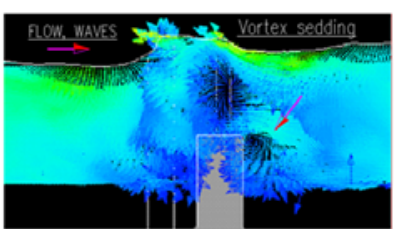

(b)

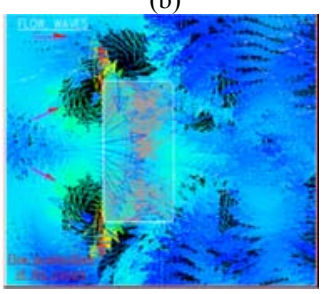

(d) (a) Elevation view of P21 Depth - Averaged Velocity at $t=18 \mathrm{~s}$; b) Elevation view of P21 Depth - Averaged Velocity at $t=52 \mathrm{~s}$; (c) Plan view of P21 Depth - Averaged Velocity at $\mathrm{t}=7 \mathrm{~s}$; (d) Plan view of P21 Depth - Averaged Velocity at $\mathrm{t}=23 \mathrm{~s}$

FIGURE IV. AVERAGED VELOCITY NEAR THE BED

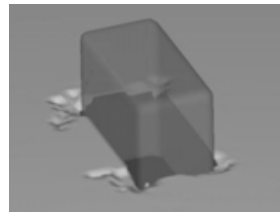

(a)

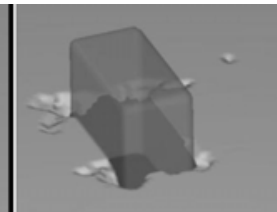

(b)

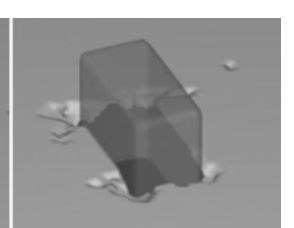

(c) (a) Scour process at $\mathrm{t}=3 \mathrm{~s}$; (b) Scour process at $\mathrm{t}=28 \mathrm{~s}$; (c) Scour process at $\mathrm{t}=$ $60 \mathrm{~s}$

\section{CONCLUSIONS}

Local scour process around the subsea caisson was studied by $3 \mathrm{D}$ Numerical simulation. The mechanism of the scour was studied and the development of the stable scour depth and stable scour time was investigated. The results can be summarized as follows:

(1) The velocity amplification at the corners of the caisson is the dominant flow mechanism that controls the maximum depth of scour around the structure. The waves, the horseshoe vortex plays a far less role than the velocity amplification.

(2) The results of scour process indicated that although the input parameters of the simulations and the experiments are a little different but scour progress and the intensity scour are quite similar.

\section{REFERENCES}

[1] Garde, R. J., Subramanya, K., and Nambudripad, K. D. Study of scour around spur-dikes. J. Hydraul. Div., Am. Soc. Civ. Eng., 87(6), 23-37, 1961.

[2] Melville, B. W. Local scour at bridge abutments. J. Hydraul.Eng., 118(4), 615-631, 1992.

[3] Laursen, E. M. An analysis of Relief Bridge scour. J. Hydraul.Div., Am. Soc. Civ. Eng., 89(3), 93-118, 1963.

[4] Breusers, H. N. C., Nicollet, G., and Shen, H. W. Local scour around cylindrical piers. J. Hydraul. Res., 15(3), 211-252, 1977.

[5] Melville, B.W., and Raudkivi, A. J. Effects of foundation geometry on bridge pier scour. J. Hydraul. Eng., 122(4), 203-209, 1996.

[6] Tsujimoto,T.,and Motohashi,K.Effect of armoring on local scour around a circular cylinder. J.Hydrosci. Hydr.Eng., 6(1), 23-34, 1988.

[7] Jia, Y., and Wang, S. S. Y. Numerical model for channel flow and morphological change studies. J. Hydraul. Eng., 125(9), 924-933, 1999.

[8] Mayerle, R., Toro, F. M., and Wang, S. S. Y. Verification of a threedimensional numerical model simulation of the flow in the vicinity of spur dikes. J. Hydraul. Res., 33(2), 243-256, 1995.

[9] Zhao, M., Zhu, X., Cheng, L., Teng, B. Experimental study of local scour around subsea caissons in steady currents. Coastal Engineering 60 (2012) 30-40, 2011.

FIGURE V. PHOTOGRAPHS OF P21 SIMULATION 